The Dianthus

A Flower Monograph. By Will Ingwersen. Pp. $128+29$ plates. (London and Glasgow: Wm. Collins, Sons and Co., Ltd., 1949.) 10s. 6d. net.

THE genus Dianthus is at once a group of plants that appeals equally to the horticulturist, to the botanist and to all those who love plants for their colour, scent and beauty. It is a genus to which the breeder has paid considerable attention, and, if the outcome of his efforts has not infrequently been to produce types that are both ill-proportioned and scentless, he has also produced others that are real acquisitions to the rock garden and the border, such as 'Charles Musgrave'. In the pages of this book Mr. W. Ingwersen writes, if all too briefly, of the many-sided attractions of these plants-something of their history as garden plants, from the sixteenthcentury carnations and pinks to the many hybrids of recent production.

The species exhibit a narrow range of colour, if we exclude the yellow Dianthus aridus and D. knappii, which latter, despite the author's criticisms, can be attractive with appropriate culture and suitable setting. Many species have long been cherished for their perfume, whether it be the fringed and scented flowers of $D$. superba, the sweet fragrance of the white $D$. squarrosus, the massive odour of the clove carnations, the elusive scent of the Sweet William, or the pervading odour of $D$. nolanus. Distribution, propagation and hybridization are concisely deait with, but most of the space is devoted to the species and garden hybrids about which the author writes with first-hand knowledge and imparts valuable experience respecting their culture. Not the least biologically interesting feature of perennial Dianthus species is their varied span of life from $D$. alpinus, which often survives only three years, to the longlived $D$. arboreus.

The work is illustrated with some excellent flower portraits in black-and-white and some, mostly less excellent, portrayals in colour. The book is one that should be on the shelves of every Dianthus enthusiast, if only for the author's illuminating comments from a wide experience.

E. J. Salisbury

\section{Engineering Science}

By H. B. Brown and A. J. Bryant. Vol. 3. Pp. viii + 531. (London : Macmillan and Co., Ltd., 1950.) 10s. net.

TN the scheme of instruction for national certificates In engineering, "Engineering Science" is a comprehensive subject which runs continuously through the three years of the ordinary course. In the third year, it comprises several branches previously treated as separate subjects, such as applied mechanics, hydraulics, strength of materials, theory of machines and heat engines. In many respects, this no doubt is an advantage as it ensures a broad foundation of knowledge being available for continued study or for application in practice, and gives the student a clearer perception of the essential unity of those branches of the subject.

One result of the syllabus is that it has made necessary a new type of text-book, and authors are presented with the problem of giving unity and balance to a treatise dealing with so many diverse phases and presenting them as a single logical subject. In the present volume, the authors have shown that this problem can be resolved within the scope of a convenient text-book. It is the third of a series designed to cover the three-year course in this subject, and graded to meet the student's attainments at each stage. In the third year the student has reached the calculus, and in this volume free use of it is made. Experimental work, testing and full-scale trials of prime movers have been given an important place, and the numerous examples have been carefully selected to give a practical association with the problems of design and operation towards which the reader is progressing. A notable feature of the presentation is the clear and concise way in which the descriptions and explanations have been given.

In addition to the requirements of the ordinary national certificate, its scope includes that of the engineering science course of the secondary technical school and also, in large measure, those of the syllabuses of the Institution of Mechanical Engineers examinations and others which demand engineering science as an integral part of their syllabuses. It should prove of considerable use to designers, draughtsmen and industrialists when questions of principle and application arise.

\section{Chymia}

Annual Studies in the History of Chemistry. Tenney L. Davis, Editor-in-Chief. (Edgar F. Smith Memorial Collection.) Vol. 2. Pp. $x+144+21$ plates. (Philadelphia : University of Pennsylvania Press; London: Oxford University Press, 1949.) 32s. net.

$\mathrm{N}$ a foreword to this second volume of "Chymia", the editors announce that Tenney Lombard Davis, distinguished as an organic chemist and a master in the field of the history of chemistry, had passed away in the interval between its publication and that of the first volume, to which he gave much of his time and energy. All interested in the history of chemistry will feel the loss which science and culture in general have sustained in his death.

The present volume contains an interesting paper by him on the pulvis fulminans. There are also papers on such subjects as the alchemical interests of Newton (in which the publication of D. McKie on this subject should certainly have been mentioned), ambergris in India, the atomic theory before Boyle (in which no mention is made of the detailed study by Partington), and Sir Kenelm Digby, as well as others. The pub. lication of successive volumes of "Chymia" continues to add to the high reputation which this series of studies in the history of chemistry has established.

\section{J. R. P.}

A Textbook of Colloid Chemistry

By Prof. Harry Boyer Weiser. Second edition. Pp. $\mathrm{x}+$ 444. (New York: John Wiley and Sons, Inc.; London : Chapman and Hall, Ltd., 1949.). 33s, net.

7 HIS is a review of colloid chemistry written mainly from the classical point of view and, within these limitations, is reasonably comprehensive. The discussion of modern techniques, such as X-ray diffraction and light scattering, is inadequate, and the reader will have to search elsewhere for useful knowledge on these topics. The documentation of the subject which, in the case of this second edition, is presumably carried to the later part of 1948, is presented in a somewhat one-sided fashion. The author has a praiseworthy grasp of American work but tends to neglect European, and particularly British, contributions to the field. These omissions detract from the value to a student of an otherwise pleasing book which treats a number of important aspects of colloid science with clarity and effectiveness. 